\title{
Formação de professores em comunidade: uma experiência com docentes que ensinam matemática nos anos iniciais
}

\section{Training of community teachers: an experience with teachers who teach mathematics in the initial years}

\author{
Simone Mumbach (profe.simonemumbach@gmail.com) \\ Progra ma de Pós-Graduação em Ensino de Ciências Exatas - Universidade Federal do Rio Grande \\ (FURG), campus Santo Antônio da Patrulha.
}

Charles dos Santos Guidotti (charles.guidotti@furg.com) Progra ma de Pós-Graduação em Ensino de Ciências Exatas - Universidade Federal do Rio Grande (FURG), ca mpus Sa nto Antônio da Patrulha.

Resumo: Este relato apresenta uma experiência formativa em comunidade aprendente, constituída por professores que ensinam Matemática nos anos iniciais. A referida comunidade, organizada em torno do estudo do Referencial Curricular Gaúcho, desenvolveu atividades assíncronas e síncronas durante o ano de 2019, totalizand o 40 horas de formação. Nesta escrita, são apresentadas as compreensões teórico-práticas emergentes sobre o processo formativo constituído. A contar do movimento de análise dos materiais desenvolvidos pelos professores em formação na comunidade, o movimento de entrelaçamento entre teoria (currículo - as expectativas) e prática (ação pedagógica - colocar o currículo em ação) pode representar uma alternativa para o aperfeiçoamento da ação docente. Aponta-se, a formação no coletivo como instrumento instigador de reflexão, possibilitando que os professores repensem suas ações através da partilha de experiências e da discussão coletiva.

Palavras-chave: Formação de professores; Comunidade aprendente; Currículo.

Resumo traduzido: A This report presents a formative experience in a learning community, made up of teachers who teach mathematics in the early years. This community, organized around the study of the Gaúcho Curriculum Reference, developed asynchronous and synchronous activities during 2019, totaling 40 hours of training. In this writing, the theoretical-practical understandings about the constituted training process are presented. Based on the movement of analysis of the materials developed by teachers in training in the community, the movement of intertwining between theory (curriculum - expectations) and practice (pedagogical action - putting the curriculum into action) can represent an alternative for the improvement of teaching action. It is pointed out, the formation in the collective as an instigating instrument of reflection, allowing teachers to rethink their actions through the sharing of experiences and collective discussion. 
Edição Especial: XVI Encontro sobre Investigação na Escola - EIE

Palavras-chave traduzidas: Teacher training; Learning community; Curriculum.

\section{INTRODUÇÃO}

A educação vive um movimento importante de mudanças curriculares a contar da homologação da Base Nacional Comum Curricular $(B N C C)^{1}$ e do Referencial Curricular Gaúcho (RCG)². A construção da BNCC teve início em 2014 e a partir de consultas e audiências públicas em dezembro de 2017 foi sancionada a versão final. De caráter normativo e elaborada com as contribuições dos profissionais da educação, a BNCC vem ao encontro da legislação vigente, definindo as aprendizagens essenciais que os estudantes devem desenvolver ao longo da Educação Básica. Nesse movimento, a construção do referencial estadual representou a oportunidade de cada território ${ }^{3}$ refletir e incorporar suas especificidades, a fim de elaborar um documento representativo da realidade local.

No Estado do Rio Grande do Sul, o RCG foi produzido ao longo de 2018, através de estudos realizados pelo grupo de redatores e da participação dos docentes nas consultas públicas. Em dezembro de 2018, o documento estadual foi homologado e, em 2019, coube às escolas e aos professores, a reestruturação de suas propostas pedagógicas, com vistas ao alinhamento entre as concepções previstas nesses documentos e a prática docente em sala de aula.

Considerando o desafio de apropriar-se do RCG e entendendo o importante papel do professor no processo educativo, esse estudo movimenta-se a partir da pergunta: Que aspectos teórico-práticos se mostram no processo de formação de uma comunidade aprendente de professores que ensinam matemática no s anos iniciais, ao colocarem em movimento o Referencial Curricular Gaúcho?

Nesse sentido, este estudo situou-se no campo da formação de professores que ensinam Matemática nos anos iniciais do Ensino Fundamental. A comunidade

\footnotetext{
${ }^{1}$ BRASIL. Base Nacional Comum Curricular. Ministério da Educação: Brasília, 2017. Disponívelem : http://basenacionalcomum.mec.gov.br/images/BNCC_EI_EF_110518_versaofinal_site.pdf. Acesso em: 8 fev. 2019.

${ }^{2}$ RIO GRANDE DO SUL. Referencial Curricular Gaúcho: Matemática. Porto Alegre, 2018. Disponívelem: http://portal.educacao.rs.gov.br/Portals/1/Files/1533.pdf. Acessoem: 8 fev. 2018.

${ }^{3}$ No RCG entende-se que o território abrange as redes municipal, estaduale priv a da. Dessa forma, os estudantes devem teras mesmas oportunidades de aprendizagens, independentemen te da rede à qual pertença.
}

Recebido em: 30 /04/ 2020

Aceito em: 19/11/2020 
Edição Especial: XVI Encontro sobre Investigação na Escola - EIE

investigada constituiu-se de professores em formação no curso Referencial Curricular Gaúcho: a Matemática dos anos iniciais em movimento.

Realizado em 2019, com o objetivo de discutir a reestruturação curricular proposta pelo Referencial Curricular Gaúcho, o curso caracterizou-se como um espaço tempo de oportunidades para os professores falarem, registrarem e problematizarem o ensino de Matemática nos anos iniciais. Isto posto, com base no campo empírico, a fenomenologia (MORAES; GALIAZZI, 2016) é assumida como meio de cons trução e ampliação de compreensões dos eventos ocorridos ao longo da formação. Para isso, recorreu-se aos princípios da Análise Textual Discursiva (ATD), com o objetivo de analisar de forma auto-organizada as informações produzidas no campo empírico. $\mathrm{O}$ corpus de análise constituiu-se dos relatos escritos pelos participantes, a partir de suas percepções, reflexões e estudos ao longo da formação.

A fim de organizar a apresentação desta experiência, o relato divide-se em três itens, após a introdução: o contexto e detalhamento das atividades - onde são descritos os movimentos iniciais de constituição da comunidade aprendente e a experiência vivida; análise e discussão do relato - descreve as compreensões obtidas a partir da análise do corpus; considerações finais - movimento de retomada da experiência e conclusão, a partir do entrelaçamento entre as interlocuções teóricas e as compreensões conquistadas na análise das informações.

\section{CONTEXTO E DETALHAMENTO DAS ATIVIDADES}

\subsection{A comunidade em formação: movimentos iniciais}

A proposta de formação apresentada neste relato teve início em dezembro de 2018, com a aplicação de um questionário/convite aos professores que ensinam matemática nos anos iniciais em São Francisco de Paula/RS. O questionário/convite teve como objetivo identificar as necessidades formativas dos referidos professores, para assim iniciar o movimento de estruturação da formação a ser ofertada. Dos 55 questionários distribuídos para docentes das redes municipal, estadual e privada, 45 retornaram respondidos. A partir dos aspectos sistematizados junto a esses instrumentos de pesquisa, destacam-se três, que serviram de base para a construção da proposta de formação: 1) a necessidade de aulas mais atrativas; 2) formas de ensinar a Matemática, 
que facilitem a aprendizagem e motivem os estudantes; 3) reflexões sobre o en sino de matemática e a troca de saberes entre pares.

Com base nesses aspectos e alinhada às concepções de diferentes autores, desenvolveu-se uma proposta de formação de professores que ensinam Matemática no s anos iniciais, a partir das relações entre a comunidade aprendente, metodologias ativas e as mudanças propostas pelo Referencial Curricular Gaúcho nesta área do conhecimento.

De acordo com Moraes e Lima (2012) “questionar o conhecer é problematizar o conhecimento". Nesse sentido, a proposta da comunidade aprendente surge como cenário capaz de suscitar esses questionamentos e problematizações do conhecimento profissional do professor. O questionamento mencionado pelos autores diz respeito às práticas pedagógicas, ao processo de construção dos saberes e aos conceitos matemáticos envolvidos diariamente em sala de aula.

[...] podemos questionar nossa compreensão do significado do a prender. [...] perguntar-nos sobre o que significa aprender e sobre os diferentes significa dos do a prender para outros. [...] Em relação ao me smo aprender, podemos questionar-nos sobre como a gimos quando pretendemos a prender algo. De que modo nos movimentamos quando pretendemos aprender a lgo, ou qua ndo pretendemos ajudar outros em sua aprendizagem. [...] Tudo pode ser questionado. Tudo pode ser modificado(MORAES; LIMA, 2012, p. 15).

Dessa forma, a incorporação da pesquisa na prática docente as sume um vié s de "questionamento reconstrutivo voltado para a educação do aluno" (DEMO, 2015, p. 47). Igualmente, a formação docente é preocupação desse estudo, sendo construída dentro da própria profissão (NÓVOA, 2009), ou seja, o professor se constrói como profissional, a partir de suas experiências.

Partindo desses pressupostos, a interação social proposta por Vygotsky (1991) ocupa função de destaque nesse processo formativo, considerando que os sujeitos aprendem a partir da relação com os outros. Nesse caso, a propos ta da comunidade aprendente configura-se como possibilitadora dessa interação e de partilha de experiências entre os professores que, em conjunto, vão se forman do e formando uns aos outros.

A utilização das metodologias ativas como procedimento na formação da comunidade representa a oportunidade do professor experienciar novas estra té gias de ensino, motivando-o a aplicá-las na prática pedagógica em sala de aula. Segundo Trigo

Recebido em: $30 / 04 / 2020$

Aceito em: 19/11/2020 
e Nunes (2011), a percepção de ensino do professor reflete sobre sua prática profissional, ele tende a reproduzir os métodos educacionais pelos quais foi educado. "Para que assimilem em sua prática pedagógica diferentes estratégias de ensino é necessário que vivencie, como aluno, essas experiências" (TRIGO; NUNES,2011, p. 17).

Acredita-se que a tríade, pesquisa/estudo, teoria e prática, contribui na formação dos professores, pois segundo Becker (2007), a docência atual caracteriza-se pela força investigadora do professor que necessita contextualizar o ensino, bem como refletir sobre os diferentes trajetos de aprendizagem dos estudantes. Nesse sentido, acontece a assunção do professor pesquisador da sua sala de aula - compartilhando-se das premissas elencadas por Marques e Becker (2007) quando destaca a "descentração" como a "capacidade de entender o pensamento do outro" (p. 60).

É só na medida em queo professor se coloca na posição de pesquisador em sala de aula que ele consegue superar o seu egocentrismo, entender o pensamento do aluno e coordenar os diferentes pontos de vista que se configuram nesse espaço escolar (MARQUES; BECKER, 2007,p. 61).

A contar dos movimentos iniciais, que aproximou os pesquisadores dos professores interessados em participar da comunidade aprendente sobre o RCG, constitui-se um grupo de 21 professores. A referida comunidade, composta por docentes das redes municipal e estadual de São Francisco de Paula, foi dividida em dois grupos: 10 no interior e 11 na sede 4 . Essa divisão em grupos surgiu por meio do desejo de contemplar os professores do interior, tendo em vista a extensão territorial do município. Normalmente, são os docentes do interior que se deslocam para a sede e, dessa vez, a pesquisadora optou por fazer esse deslocamento e ofertar a formação mais perto da residência e do local de trabalho desses professores.

No que tange à caracterização dos sujeitos, o tempo de atuação, a graduação e a pós-graduação dos participantes da comunidade. A tabela 1 apresenta a sistematização desses aspectos.

\footnotetext{
${ }^{4}$ Entende-se por sede a área urbana do município.
}

Recebido em: $30 / 04 / 2020$ 
Tabela 1 - Ca racterização dos sujeitos da comunidade

\begin{tabular}{|c|c|c|}
\hline Tempo de experiência & Graduação & Pós-graduação \\
\hline $0-4$ anos: $19 \%$ & Peda gogia: 13 & Administração, Supervisão e OrientaçãoEscolar \\
\hline 5-9 anos: $5 \%$ & Matemática: 5 & 7 \\
\hline 10-14 anos: $9 \%$ & Geografia: 1 & Psicopedagogia: 6 \\
\hline 15-19 a nos: $43 \%$ & Letras/Espanhol: 1 & Neuropsicopedagogia: 3 \\
\hline $20-24$ anos: $14 \%$ & Peda gogia em curso: 1 & Informática: 1 \\
\hline \multirow[t]{3}{*}{$25-29$ a nos: $10 \%$} & $\begin{array}{l}\text { Educação Física em } \\
\text { curso: } 1\end{array}$ & $\begin{array}{l}\text { Ensino Religioso: } 2 \\
\text { Filosofia e Sociologia: } 1\end{array}$ \\
\hline & Ma temática em curso: 1 & $\begin{array}{l}\text { Docência em Educação Infantile Anos Iniciais: } 2 \\
\text { Educação Especial e In clusiva: } 1\end{array}$ \\
\hline & & $\begin{array}{l}\text { Alfabetização e Letramento: } 1 \\
\text { Mídias na Educacão; } 1\end{array}$ \\
\hline
\end{tabular}

Fonte: autora

Com base na tabela apresentada, percebe-se que, em sua maioria, os participantes da comunidade são professores com mais de 15 anos de experiência profissional. Sendo assim, a formação em comunidade possui o desafio de desacomodar e movimentar esses docentes, no sentido de perceber e pensar sobre suas ações pedagógicas, direciona das para as mudanças curriculares atuais, ou seja, "refletir sobre sua prática em suas múltiplas dimensões" (RIO GRANDE DO SUL, 2018, p. 34). Outro aspecto relevante consiste no fato de que mais da metade dos docentes possuem graduação em Pedagogia. Além disso, há uma diversidade nas formações, sendo que o grupo contém, inclusive, professores que ainda não concluíram sua formação inicial. A diversidade exprimida nos cursos de graduação é significativamente ampliada, quando analisada a formação em nível de pós-graduação, conforme a terceira coluna da tabela.

Ademais, a comunidade também possuía três participantes cursando especialização em Matemática e dois participantes com Mestrado em Tecnologias concluído. É possível vislumbrar que os professores da comunidade advêm de diferentes bases formativas e, com isso, a apropriação do RCG de matemática dos anos iniciais, assim como a reflexão acerca de suas práticas retratam o movimento pretendido e necessário para que seja possível o alinhamento entre os saberes dos docentes e as novas mudanças curriculares. 
Edição Especial: XVI Encontro sobre Investigação na Escola - EIE

ISSN: $2595-4520$

Vol. 4, n. 2. 2021

Cabe ressaltar que uma proposta formativa alicerçada nas premissas da comunidade aprendente e metodologias ativas não é a solução para todos os problem as enfrentados pelos professores, mas pode representar um caminho para dirimir, em parte, os anseios e desafios enfrentados diariamente em sala de aula. Com isso, acredita-se na qualificação da prática pedagógica, alvitrando-se melhoras na aprendizagem matemática dos estudantes dos anos iniciais. Na próxima seção, são relatados os movimentos que constituíram os encontros de formação realizados com a comunidade.

\subsection{A experiência vivida}

A contar dos entendimentos descritos ao longo deste relato, como também das necessidades formativas apontadas pelos professores no questionário/convite, a formação proposta aos grupos fundamenta-se nas concepções da comunidade aprendente (GALIAZZI et al., 2017; FREITAS, 2010; BRANDÃO, 2005) e das metodologias ativas (MORÁN, 2015; DIESEL; BALDEZ; MARTINS, 2017). Registrou-se que o objetivo principal da formação consistiu na problematização do Referencial Curricular Gaúcho de Matemática para os anos iniciais do Ensino Fundamental.

Com base nisso, são ressaltados alguns aspectos organizacionais que caracterizam a comunidade em formação:

- As atividades a distância foram realizadas na plataforma do Google sala de aula. Para tanto, foram criadas duas turmas na plataforma e, para cada uma, as atividades e materiais utilizados nos encontros foram postados. As atividades a distância ocorreram no período entre um encontro presencial e outro, com o intuito de ampliar as discussões e suscitar reflexões e escritas, conforme os objetivos propostos.

- A dinâmica e a organização de cada encontro foram planejados de acordo como caminho percorrido pelo grupo, ou seja, propôs-se uma formação horizontal, on de os participantes e as discussões de cada encontro definissem os próximos passos da comunidade.

- Proposta de escrita de um "diário de movimentos" - relatos dos encontros escritos por cada participante, a partir das discussões e problematizações. Esses diários fizeram parte do corpus de análise da pesquisa.

Recebido em: 30 /04/ 2020

Aceito em: 19/11/2020 
Desde a estruturação descrita, a formação da comunidade constituiu-se de atividades ${ }^{5}$ diversas, com o objetivo de problematizar o RCG de matemática para os anos iniciais, aliando-o às práticas dos professores e reflexões oriundas desse contex to. A cada encontro os docentes foram instigados a refletir e discutir, coletivamente, as competências específicas propostas pelo RCG, como também estabelecer relações com suas práticas e as atividades propostas.

Cabe destacar que os encontros formativos foram sendo planejados e estruturado $s$ a partir das percepções e anseios trazidos pela comunidade em formação. Reconhecemos que propor uma formação para colegas de profissão é sempre um grande desafio, ainda mais quando o grupo possui larga experiência docente e ampla base formativa.

Nesse sentido, experenciar as atividades e os métodos e, também, partilhar experiências e anseios constituíram algumas das potencialidades nesta proposta de formação em comunidade. A ideia de formar uns aos outros de forma colaborativa, sem que fossem apresentadas "receitas prontas", fortaleceu os laços entre os participantes, criando um ambiente de confiança para expressar e discutir aspectos que considerassem relevantes.

Em contrapartida, a utilização do ambiente virtual de aprendizagem não surtiu o resultado esperado. Embora a proposta tenha incluído ativid ades a distância, percebeu se que a participação e o engajamento foram, significativamente, mais relev an tes nos encontros presenciais do que nas discussões propostas no AVA.

\section{ANÁLISE E DISCUSSÃO DO RELATO}

Constituir compreensões a partir do processo de formação da comunidade aprendente de professores que ensinam matemática nos anos iniciais caracteriza-se como o cerne desse estudo. Com isso, buscou-se, neste estudo, responder a seguinte interrogação: Que aspectos teórico-práticos se mostram no processo de formação de uma comunidade aprendente de professores que ensinam matemática no sanos iniciais, a colocarem em movimento o Referencial Curricular Gaúcho? De caráter qualitativo e

5 Encontros formativos: https://drive.google.com/open?id=128ZoXQpCL9lpxtjX5N6Z9CY6paN6oOeSgVxTfjgpP4

Recebido em: 30 /04/ 2020

Aceito em: 19/11/2020 
Edição Especial: XVI Encontro sobre Investigação na Escola - EIE

de cunho fenomenológico, a análise desenvolvida traz uma abordagem direta dos fenômenos, valorizando a subjetividade dos sujeitos envolvidos, a partir da linguagem expressa nas informações coletadas (MORAES; GALIAZZI, 2016).

Para a construção das compreensões emergentes do processo de formação da comunidade aprendente de professores que ensinam Matemática, utilizou-se a Análise Textual Discursiva que, segundo Moraes e Galiazzi (2016, p.13), tem "a finalida de de produzir novas compreensões sobre os fenômenos e discursos". Para os autores, o movimento da ATD tem por objetivo "a reconstrução de conhecimentos existentes sobre os temas investigados" (MORAES; GALIAZZI, 2016, p. 33) ao invés do levantamento e testagem de hipóteses.

Nessa lógica, o processo de análise teve início na definição do corpus da pesquisa, tendo em vista a vasta quantidade de material produzido ao longo da formação. Dentre os materiais mencionados, citam-se os cartazes, as escritas realizadas a cada encontro presencial, as produções realizadas no AVA e os diários de movimentos. A delimitação do corpus foi o momento em que a pesquisadora selecionou o conjunto de documentos que possibilitasse resultados válidos e representativos para o estudo (MORAES; GALIAZZI, 2016). Dessa forma, o corpus selecionado constitui-se dos diários de movimentos entregues no último encontro presencial e dos relatos escritos ao longo dos encontros presenciais.

Partindo desses pressupostos, a análise foi estruturada a partir de uma sequência composta por três componentes: desmontagem dos textos (unitarização), estabelecimento de relações (categorização) e a captação do novo emergente (MORAES; GALIAZZI, 2016). A desmontagem dos textos ou unitarização caracterizase pelo movimento inicial de construção de compreensões, onde foram obtidas 138 unidades de significado. É nesse momento que o pesquisador examina, minuciosamente, os textos que compõem o corpus, em busca de unidades que confiram significado ao fenômeno pesquisado.

O movimento de categorização é o próximo passo realizado a partir das unidades de significado. De acordo com Moraes e Galiazzi (2016), a categorização consiste no estabelecimento de relações entre as unidades de significado, com o intuito de combinálas e reuni-las em categorias com elementos afins. A partir disso, as 138 unidades de 
Edição Especial: XVI Encontro sobre Investigação na Escola - EIE

significado resultaram em 7 (sete) categorias intermediárias, onde cada uma repres enta um conjunto de unidades de significado com ideias semelhantes, o pesquisador as su me a tarefa de estabelecer as relações possíveis entre elas determinando, assim, as categorias finais emergentes da pesquisa. A partir das 7 (sete) categorias intermediárias, num movimento de reflexão e aglutinação, chegou-se a 2 (duas) categorias finais, conforme demonstrado na tabela 2 .

Tabela 2 - Composição das categorias finais

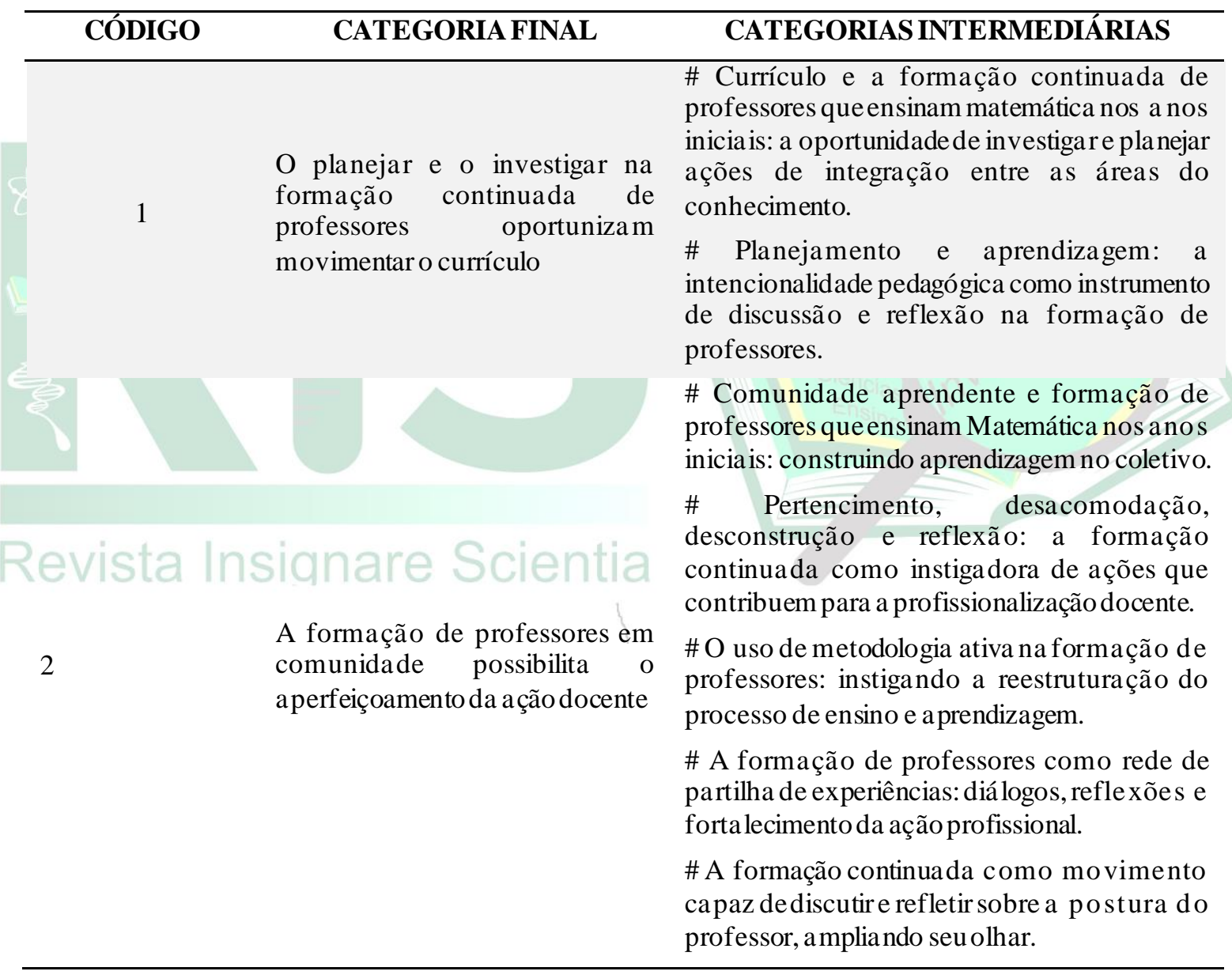

Fonte: a utora.

Por fim, o terceiro componente da sequência proposta pela ATD configura-se no movimento de captar o emergente. Moraes e Galiazzi (2016) afirmam que esse é o momento em que acontece a "emergência renovada do todo" (Ibid., p. 34), ou seja, o metatexto produzido pelos pesquisadores caracteriza-se pela escrita das compreensões 
alcançadas através do processo de análise do corpus. Diante desses pressupostos, a ideia de unir a comunidade aprendente e as metodologias ativas pode promover a movimentação dos participantes em prol da investigação contínua de seu fazer pedagógico, aliada à colaboração entre colegas de profissão. A inserção do estudo do Referencial Curricular Gaúcho representa a necessidade que o professor tem de apropriar-se das mudanças curriculares para que sejam incorporadas à sua prática pedagógica. Além disso, não se pode ensinar algo sem que seja, minuciosamente, conhecido.

\section{CONSIDERAÇÕES FINAIS}

O presente estudo possibilitou análises e discussões acerca dos aspectos provenientes da formação em comunidade de professores que ensinam matemática nos anos iniciais. Registrou-se, a partir das categorias emergentes na análise do corpus, a necessidade de embasar a formação continuada nos documentos curriculares, bem como nas experiências profissionais dos docentes. Esse movimento de entrelaça men to en tre teoria (currículo - as expectativas) e prática (ação pedagógica - colocar o currículo em ação) pode representar uma alternativa para o aperfeiçoamento da ação docente.

Dessa forma, distinguiu-se a formação no coletivo como instrumen to in stigad or de reflexão, possibilitando que os professores repensem suas ações através da partilha de experiências e da discussão coletiva. A valorização dos saberes trazidos por cada docente representa o ponto de convergência entre suas concepções e as novas construções possíveis, a partir das experiências vividas / discutidas na formação. Para, além disso, a utilização de metodologias ativas na formação oportuniza que os professores experenciem diferentes estratégias, que podem contribuir no processo de ensino e aprendizagem.

Cabe ressaltar que as mudanças curriculares estão à mercê do trabalho do professor, ou seja, essas mudanças somente alcançarão as salas de aula e os estudantes se os docentes assim o fizerem. Nessa lógica, a formação continuada assume papel de destaque, pois caracteriza-se como um momento capaz de trazer à tona os an seios e as preocupações do professor, possibilitando que sejam discutidos, estudados e refletidos de forma coletiva. 


\section{REFERÊNCIAS}

BECKER, Fernando; MARQUES, Tânia B. I. (Orgs.). Ser Professor é Ser

Pesquisador. Porto Alegre: Mediação, 2007.

BRANDÃO, Carlos Rodrigues. Encontros e caminhos: formação de educadoras (es) ambientais e coletivos educadores. Brasília: MMA, Diretoria de Educação Ambiental, 2005. p. 83-92. Disponível em: http://www.mma.gov.br/estruturas/educamb/ _arquivos/encontros.pdf. Acesso em: 13 nov. 2018.

BRASIL. Base Nacional Comum Curricular. Ministério da Educação: Brasília, 2017. Disponível em: http://basenacionalcomum.mec.gov.br/images/BNCC_EI_EF_ 110518_versaofinal_site.pdf. Acesso em: 8 fev. 2019.

DEMO, Pedro. Educar pela pesquisa. Campinas: Autores Associados, 2015.

DIESEL, Aline; BALDEZ, Alda Leila Santos; MARTINS, Silvana Neumann. Os princípios das metodologias ativas de ensino: uma abordage m teórica. Revista Thema, v. 14, n. 1, 2017. Disponível em: http://revistathema.ifsul.edu.br/index.php/thema/ article/view/404/295. Acesso em: 2 fev. 2018.

FREITAS, Diana Paula Salomão de. A perspectiva da comunidade aprendente nos processos formativos de professores pesquisadores educadores ambientais. 2010. 225f. Dissertação (Mestrado) - Universidade Federal do Rio Grande, Programa de PósGraduação em Educação Ambiental, Rio Grande, 2010.

GALIAZZI, Maria do Carmo et al. Narrativas de Comunidades Aprendentes em Educação Ambiental. Revista de Educação Ambiental, v. 22, n. 2, 2017.

\section{MARQUES, Tânia B. I; BECKER, Fernando (Orgs.). Ser Professor é Ser} Pesquisador. Porto Alegre: Mediação, 2007.

MORAES, Roque; LIMA, Valderez Marina do Rosário (orgs.). Pesquisa em sala de aula; tendências para a educação em novos tempos. Porto Alegre: EDIPUCRS, 2012, 3. ed.

MORAES, Roque; GALIAZZI, Maria do Carmo. Análise Textual Discursiva. Ijuí: Ed. Unijuí, 2016.

MORÁN, José. Mudando a educação com metodologias ativas. Coleção Mídias Contemporâneas. Convergências Midiáticas, Educação e Cidadania: aproximações jovens. PG: Foca Foto-PROEX/UEPG, 2015. Disponível em:

http://www2.eca.usp.br/moran/wpcontent/uploads/2013/12/mudando_moran.pdf.

Acesso em: 31 jan. 2019.

NÓVOA, António. Para uma formação de professores construída dentro da profissão .

Revista Educacion, v.350, 2009. Disponível em:

http://www.revistaeducacion.educacion.es/re350/re350_09por.pdf. Acesso em: 23 out. 2018.

Recebido em: 30 /04/ 2020

Aceito em: 19/11/2020 
Edição Especial: XVI Encontro sobre Investigação na Escola - EIE

RIO GRANDE DO SUL. Referencial Curricular Gaúcho: Matemática. Porto Alegre, 2018. Disponível em: http://portal.educacao.rs.gov.br/Portals/1/Files/1533.pdf. Acesso em: 8 fev. 2018.

TRIGO, Carmen; NUNES, Wallace. Experimentos didáticos no ensino da matemática: Orientações pedagógicas. Rio de Janeiro: IFRJ 2011.

VYGOTSKY, Lev S. A formação social da mente. São Paulo: Martins Fonte, 1991. 